\title{
Gastrostomy placement in children: the method of operation
}

\begin{abstract}
Purpose: The aim of this report is to summarize recent reports comparing the outcomes and the complications between the two most adopted procedures for gastrostomy placement in children:percutaneous endoscopic Gastrostomy (PEG) and laparoscopic Gastrostomy (LG)
\end{abstract}

Methods: Electronic databases were queried for comparative studies of the two most common insertion techniques, including the PEG and LG. Major Complications were defined as reoperation within 30 days or death.

Results: Recent studies comparing PEG and LG revealed an increased risk in major complications with PEG.

Conclusion: PEG is associated with an increased risk of major complications when compared to the LG approach.

Keywords: gastrostomy, laparoscopy, percutaneous endoscopy, children, outcome, complications
Volume 4 Issue 4 - 2017

\section{Einar Arnbjörnsson}

Department of Pediatric Surgery, Skåne University Hospital and the Department of Clinical Sciences, Sweden

\author{
Correspondence: Einar Arnbjörnsson, MD, PhD, Department \\ of Pediatric Surgery, Skåne University Hospital and the \\ Department of Clinical Sciences, Pediatrics, Lund University, 22 I \\ 85 Lund, Sweden, Tel +467-064-963-80, \\ Email einar.arnbjornsson@telia.com
}

Received: May 13, 2017 | Published: June 19, 2017

\section{Introduction}

The various technical options that have been described for gastrostomy tube placement in children include the time honored Stamm procedure, percutaneous endoscopic gastrostomy (PEG), percutaneous fluoroscopy-guided gastrostomy, several types of laparoscope-assisted gastrostomy (LG), video-assisted gastrostomy, and a combined laparoscopic and endoscopic approach as well as different variations of the methods used in the hands of the reporting surgeons. ${ }^{1}$ Minimally invasive procedures for enteral access in children have evolved over the years, resulting in various techniques of gastrostomy tube placement. The two most common techniques are PEG and LG. This study compares the reported outcomes of both procedures exclusively in children. Consensus is lacking as to which procedure, if any, is superior.

Increasing evidence has suggested a lower rate of serious complications following LG in comparison to PEG, open gastrostomy, or other techniques. ${ }^{1,2}$ The advantages of video-assisted gastrostomy are placement of the gastrostomy under direct visualization and the performance of the gastropexy. ${ }^{1-6}$ Complication rates associated with laparoscopic- or video-assisted or fully laparoscopic techniques have been reported to be inferior to those associated with other techniques. $^{7-11}$ However, previous studies examining postoperative complications in children undergoing LG have included only small numbers of patients and have had various durations of follow-up and without any comparison with other techniques for gastrostomy placement. ${ }^{12-20}$ The same applies to the PEG technique. ${ }^{21-24}$ PEG and LG are widely used in the pediatric population. The aim of this literature review was to determine which one of the two procedures is the most effective and safe method.

\section{Methods}

Electronic databases were queried for comparative studies of the two most common insertion techniques, including the PEG and
LG. Complications are generally classified as major or minor. ${ }^{25}$ Major complications, the object of this review, were defined as reoperation within 30days or death. Major complications were to include pneumoperitoneum, hemorrhage, duodenal hematoma, colon injuries, liver injuries, small bowel injuries, gastric perforation, gastro-colic fistula, peritonitis, and buried bumper syndrome. ${ }^{26}$ Minor complications, in line with previous studies were to include granuloma, infection requiring antibiotic treatment, leakage, vomiting, pain, and dislocation of the button. ${ }^{12-20}$

\section{Results}

Eleven reports were found discussing the comparison of the PEG and LG. 1,2,7,11,27-33 All revealed a significantly increased risk in major complications with PEG. During the same period, there were no reports showing lower number of major complications after PEG compared with LG in children. The operating time for LG is $2-3$ times longer than the quarter of an hour usually needed for the PEG insertion. There is ashorter time to enteral nutritionafter LG insertion compared by PEG.

\section{Discussion}

This study aimed to compare two different techniques for placement of gastrostomy tubes in a pediatric population. The PEG procedure involves a blind puncture through the abdominal cavity while the LG procedure involves visualization of the stomach through an umbilical port and a selection of a second epigastric gastrostomy site to select and anchor the stomach with sutures prior to the placement of a low profile gastrostomy feeding device. Several major complications have been associated with PEG. On the contrary, only a few major complications, including gastric perforation, gastrostomy dislodgment, and conversion to open procedure have been described in association with LG. Minor complications have been shown to diminish significantly over time whereas pain and dislodgement of the gastrostomy device does not. ${ }^{34}$ The minor complications, on the 
other hand, are equally encountered in both PEG and video-assisted gastrostomy. ${ }^{35}$ The operating time needed for LG is $2-3$ times longer than the quarter of an hour needed for the PEG insertion. This advantage in operative time is outweighed by the increased safety profile of LG insertion. The data on the shorter time to enteral nutrition after LG insertion compared by PEG seem to be hampered by local traditions. Buried bumper syndrome, in which the internal fixation device migrates alongside the tract of the stoma outside the stomach, is known to be a severe complication to PEG placement only. ${ }^{36}$

\section{Conclusion}

Summary of the findings of the reports of PEG compared with LG in the literature indicates that LG should be the preferred method of gastrostomy placement in children. The results suggest that by performing LG in children it is possible to avoid the serious intestinal fistula complications caused by a blind puncture through the abdominal cavity when performing the PEG.

Thus, PEG is associated with an increased risk of major complications when compared to the LG approach. Some advantages in operative time for PEG appear outweighed by the increased safety profile of LG insertion as well as shorter time to enteral nutrition after LG. Because of the lack of well-designed studies, we have to be cautious in making definitive conclusions comparing PEG to LG To decide which type of gastrostomy placement is best practice in pediatric patients, randomized controlled trials comparing PEG to LG are highly warranted. Prospective analysis of the various techniques is needed to confirm which minimally invasive techniques for gastrostomy tube placement are associated with a less complicated post-operative course. The most important question of how we manage to make the performance of a gastrostomy placement in children still safer remains to be answered.

\section{Acknowledgements}

None.

\section{Conflict of interest}

The author declares that no financial interest or any conflict of interest exists.

\section{References}

1. Merli L, De Marco EA, Fedele C, et al. Gastrostomy placement in children: percutaneous endoscopic gastrostomy or laparoscopic gastrostomy? Surg Laparosc Endosc Percutan Tech. 2016;26(5):381-384.

2. Lantz M, Hultin Larsson H, Arnbjörnsson E. Literature review comparing laparoscopic and percutaneous endoscopic gastrostomies in a pediatric population. Int J Pediatr. 2010;2010:507616.

3. Shimizu Y, Okuyama H, Sasaki T, et al. Laparoscopic-assisted percutaneous endoscopic gastrostomy: a simple and efficient technique for disabled elderly patients. J Parenter Enteral Nutr. 2014;38(4):475-480.

4. Yu SC, Petty JK, Bensard DD, et al. Laparoscopic-assisted percutaneous endoscopic gastrostomy in children and adolescents. JSLS. 2005;9(3):302304.

5. Idowu O, Driggs XA, Kim S. Laparoscopically assisted antegrade percutaneous endoscopic gastrostomy. J Pediatr Surg. 2010;45(1):277279.
6. Given MF, Hanson JJ, Lee MJ. Interventional radiology techniques for provision of enteral feeding. Cardiovasc Intervent Radiol. 2005;28(6):692703.

7. Akay B, Capizzani TR, Lee AM, et al. Gastrostomy tube placement in infants and children: is there a preferred technique? J Pediatr Surg. 2010;45(5):1147-1152.

8. Jones VS, La Hei ER, Shun A. Laparoscopic gastrostomy: the preferred method of gastrostomy in children. PediatrSurg Int. 2007;23(11):10851089.

9. Vervloessem D, Van Leersum F, Boer D, et al. Percutaneous endoscopic gastrostomy (PEG) in children is not a minor procedure: risk factors for major complications. Semin Pediatr Surg. 2009;18(2):93-97.

10. Zamakhshary M, Jamal M, Blair GK, et al. Laparoscopic vs percutaneous endoscopic gastrostomy tube insertion: a new pediatric gold standard? $J$ Pediatr Surg. 2005;40(5):859-862.

11. Liu R, Jiwane A, Varjavandi A, et al. Comparison of percutaneous endoscopic, laparoscopic and open Gastrostomy insertion in children. Pediatr Surg Int. 2013;29(6):613-621.

12. Backman T, Sjövie H, Kullendorff CM, et al. Continuous double U-stitch gastrostomy in children. Eur J Pediatr Surg. 2010;20:14-17.

13. Mikaelsson C, Arnbjörnsson E. Single-puncture laparoscopic gastrostomy in children. PediatrSurg Int. 1998;14(1):43-44.

14. Arnbjörnsson E, Larsson LT, Lindhagen T. Complications of laparoscopy-aided gastrostomies in pediatric practice. J Pediatr Surg. 1999;34(12):1843-1846.

15. Andersson L, Mikaelsson C, Arnbjörnsson E, et al. Laparoscopy aided gastrostomy in children. Ann Chir Gynaeco. 1997;86(1):19-22.

16. Norén E, Gunnarsdóttir A, Hanséus K, et al. Laparoscopic gastrostomy in children with congenital heart disease. J Laparoendosc Adv Surg Tech A. 2007;17(14):483-489.

17. Backman T, Berglund Y, Sjövie H, et al. Complications of video-assisted gastrostomy in children with or without a ventricul operitoneal shunt. PediatrSurg Int. 2007;23(7):665-668.

18. Plantin I, Arnbjörnsson E, Larsson LT. No increase in gastroesophageal reflux after laparoscopic gastrostomy in children. PediatrSurg Int. 2006;22(7):581-584.

19. Arnbjörnsson E, Backman T, Mörse H, et al. Complications of videoassisted gastrostomy in children with malignancies or neurological diseases. Acta Paediatr. 2006;95(5):467-470.

20. Backman T, Arnbjörnsson E, Berglund Y, et al. Video-assisted gastrostomy in infants less than 1year. PediatrSurg Int. 2006;22(3):243-246.

21. Hansen E, Qvist N, Rasmussen L, et al. Postoperative complications following percutaneous endoscopic gastrostomy are common in children. Acta Paediatr. 2017;106(7):1165-1169.

22. Koca T, Sivrice AÇ, Dereci S, et al. Percutaneous endoscopic gastrostomy in children: a single center experience. Turk Pediatri Ars. 2015;50(4):211216.

23. Szlagatys-Sidorkiewicz A, Borkowska A, Popińska K, et al. Complications of PEG are not related to age - The result of 10-year multicenter survey. Adv Med Sci. 2016;61(1):1-5.

24. McSweeney ME, Kerr J, Jiang H, et al. Risk factors for complications in infants and children with percutaneous endoscopic gastrostomy tubes. $J$ Pediatr. 2015;166(6):1514-1519. 
25. Schrag SP, Sharma R, Jaik NP, et al. Complications related to percutaneous endoscopic gastrostomy (PEG) tubes. A comprehensive clinical review. $J$ Gastrointest Liver Dis. 2007;16(4):407-418.

26. Khalil Q, Kibria R, Akram S. Acute buried bumper syndrome. South Med J. 2010;103:1256-1258.

27. Landisch RM, Colwell RC, Densmore JC. Infant gastrostomy outcomes: The cost of complications. J Pediatr Surg. 2016;51(12):1976-1982.

28. Petrosyan M, Khalafallah AM, Franklin AL, et al. Laparoscopic gastrostomy is superior to percutaneous endoscopic gastrostomy tube placement in children less than 5years of age. J Laparoendosc Adv Surg Tech A. 2016;26(7):570-573.

29. Suksamanapun N, Mauritz FA, Franken J, et al. Laparoscopic versus percutaneous endoscopic gastrostomy placement in children: Results of a systematic review and meta-analysis. J Minim Access Surg. 2017;13(2):8188 .

30. Sulkowski JP, De Roo AC, Nielsen J, et al. A comparison of pediatric gastrostomy tube placement techniques. PediatrSurg Int. 2016;32(3):269 275.
31. Baker L, Beres AL, Baird R. A systematic review and meta-analysis of gastrostomy insertion techniques in children. $J$ Pediatr Surg. 2015;50(5):718-725.

32. Wragg RC, Salminen H, Pachl M, et al. Gastrostomy insertion in the $21 \mathrm{st}$ century: PEG or laparoscopic? Report from a large single-centre series. PediatrSurg Int. 2012;28(5):443-448.

33. Jones VS, La Hei ER, Shun A. Laparoscopic gastrostomy: the preferred method of gastrostomy in children. PediatrSurg Int. 2007;23(11):10851089.

34. Salö M, Santimano A, Helmroth S, et al. Long-term outcomes of children undergoing video-assisted gastrostomy. Pediatr Surg Int. 2017;33(1):8590 .

35. Wragg RC, Salminen H, Pachl M, et al. Gastrostomy insertion in the $21 \mathrm{st}$ century: PEG or laparoscopic? Report from a large single-centre series. PediatrSurg Int. 2012;28(5):443-448.

36. Cyrany J, Rejchrt S, Kopacova M, et al. Buried bumper syndrome: A complication of percutaneous endoscopic gastrostomy. World $J$ Gastroenterol. 2016;22(2):618-627. 